\title{
PSEUDO-ANALYTIC FINITE PARTITION APPROACH TO TEMPERATURE DISTRIBUTION PROBLEM IN HUMAN LIMBS
}

\author{
V.P. SAXENA \\ School of Mathematics and Allied Sciences \\ Jiwaji University \\ Gwalior \\ and
}

J.S. BINDRA

Department of Applied Sciences

Mathematics Secticn

G.N. Engineering College

Ludhiana

(Received March 10, 1987 and in revised form September 8, 1988)

\begin{abstract}
The main object of this paper is to introduce the Pseudo Analytic Finite Partition method and to illustrate its use in solving physiological heat distribution problems pertaining to limbs and simllar body organs. A two dimensional circular region resembling the cross section of a human or animal 1 imb is considered. The biological properties are assumed to vary along the radial direction. The theoretical model incorporates the effect of blood mass flow and metabolic heat generation. The region is divided into annular sub-regions and Ritz variational finite element method is applied along the radial direction, while for the angular direction, Fourier Series has been used due to uniformity in each annular part.
\end{abstract}

KEY WORDS AND PHRASES. Blood mass flow rate, rate of metabolic heat generation, variational finite element method.

1980 AMS SUBJECT CLASSIFICATION CODES.

\section{INTRODUCTION.}

A human body maintains its body core temperature at a uniform temperature under the normal atmospheric conditions. In order to maintain this core temperature, parameters like rate of blood mass flow, rate of metabolic heat generation and, thermal conductivity vary in response to changes in atmospheric conditions. However, in extreme parts of a human body, the core temperature is not uniform at low atmospheric temperatures, where the core temperature of 1 imbs varies extensively as we move away from the body core. This may be because the arterial blood has cooled down while traveling towards the extremities. The heat flow in in-vivo tissues is given by W. Perl [1] as given below. 


$$
\rho \bar{c} \frac{\partial u}{\partial t}=\operatorname{Div}(K \operatorname{grad} u)+m_{b} c_{b}\left(u_{b}-u\right)+s
$$

where $, \rho, \bar{c}, K$ and $S$ are respectively the density, specific heat, thermal conductivity and, rate of metabolic heat generation in tissues. $m_{b}$ and $c_{b}$ are the mass blood flow rate and specific heat of the blood respectively. W. Perl [1] derived and used this equation to study simple problems of heat flow in tissue medium. Chao, Eisley and Yang [2] and Chao and Yang [3] also studied temperature distributions in infinite tissue mediums. Cooper and Trezek [4] obtained a solution for a cylindrical symmetry with all the parameters as constant. Saxena [5,6], Saxena and Arya $[7,8]$, and Saxena and Bindra $[9,10]$ used this model to study temperature distributions in skin and subcutaneous tissues using analytical and numerical techniques. This study was performed for a one dimensional steady state case. Later Arya [11], Arya and Saxena [12] and Saxena and Bindra [13] investigated this problem for a two dimensional steady state case in skin and subcutaneous tissues. Here a cylindrical limb having circular cross section with layers of tissues with different properties is considered. The outer boundary is assumed to be exposed to the environment and heat loss takes place due to convection, radiation and, evaporation. The innermost solid cross section is assumed to be at a known variable temperature. This case may occur when one side of the limb contains major blood vessels and thus heated constantly by the blood comming out of main trunk.

\section{MATHEMATICAL FORMULATION.}

Equation (1.1) in polar steady state form can be written as:

$$
\frac{\partial}{\partial r}\left(K r \frac{\partial u}{\partial r}\right)+\frac{K}{r} \frac{\partial^{2} u}{\partial r^{2}}+m_{b} c_{b} r\left(u_{b}-u\right)+r S=0 .
$$

The region is divided into $N$ layers with inner and outer radil equal to $a_{0}$ and $a_{N}$ respectively. (see Fig.1).

The boundary and initial conditions imposed are

$$
\text { and } \begin{aligned}
\left|-k \frac{\partial u}{\partial r}\right| & =h\left(u-u_{a}\right)+L E \\
r=a_{N} & \quad u\left(a_{0}, \theta\right)=f(\theta)=u_{0}
\end{aligned}
$$

where $f(\theta)$ is known. Here $h$ is the heat transfer coefficient and, $L$ and $E$ are respectively the latent heat and rate of sweat evaporation. $\mathrm{S}$ is assigned temperature dependent values given by

$$
S=s\left(u_{b}-u\right) / u_{b} \text {, where } s \text { is constant. }
$$

Thus equation (2.1) along with boundary conditions (2.2) and (2.3) is reduced to descretized polar variational form as given below:

$$
\begin{aligned}
& I_{i}=\frac{1}{2} \int_{\bar{a}_{1-1}}^{\bar{a}_{1}}\left[\bar{r} K_{i}\left(\frac{\partial v^{(i)}}{\partial r}\right)-\frac{K_{1}}{\bar{r}}\left(\frac{\partial^{2} v^{(1)^{2}}}{\partial \bar{\theta}^{2}}+\bar{M}_{i} \bar{r} v^{(1)^{2}}\right] d \bar{r}+\delta_{1}, i=1(1) N\right. \\
& \text { where } \delta_{N}=\left[\frac{h}{2}\left(v^{(N)}-v_{a}\right)^{2}-L E v^{(N)} / u_{b}\right] \quad{ }_{r}=a_{N} \\
& \delta_{1}=0,1=1(1) \mathrm{N}-1
\end{aligned}
$$


$\bar{a}_{i}=a_{i} / a_{0}, a_{i}(i=1(1) N)$ is the external radius of $i$ th annular region as shown in Fig.

(1), $K_{1}, \bar{M}_{1}$ and $v^{(i)}$ are values of $K, \bar{M}$ and, $v$ in the ith region,

$$
\bar{M}=a_{0}^{2}\left(m_{b} c_{b}+s / u_{b}\right), \bar{r}=r / a_{0}, v=\left(u_{b}-u\right) / u_{b}, v_{a}=\left(u_{b}-u_{a}\right) / u_{b},
$$

The following linear shape functions have been taken for each region:

$$
v^{(i)}=\frac{a_{i} v_{i-1}-a_{i-1} v_{1}}{\bar{a}_{1}-\bar{a}_{i-1}}+\frac{v_{i}-v_{i-1}}{\bar{a}_{i}-\bar{a}_{i-1}} \bar{r} \text {. }
$$

Evaluating integrals $(2.4)$ and assembling these we get

$$
I=\sum_{1-1}^{N} I_{1}
$$

Now I is extremized with respect to $v_{i}$ and the following equations are obtained:

$$
\sum_{j=0}^{N}\left(E_{j}^{i} v_{j}+F_{j}^{i} \frac{\partial^{2} v_{j}}{\partial \theta^{2}}\right)=H_{i}
$$

Where $E_{j}^{i}, F_{j}^{i}$ and $H_{i}$ are constants depending upon physical and physiological parameters.

Now Fourier Series is applied to eliminate the $\theta$ variable from the equation (2.7). We take

and

$$
v_{\circ}=A_{o \circ}+\sum_{n=1}^{\infty}\left(A_{n o} \cos n \theta+B_{n o} \operatorname{Sinn} \theta\right)
$$

$$
v_{1}=A_{01}+\sum_{n=1}^{\infty}\left(A_{n 1} \cos n \theta+B_{n i} \operatorname{Sin} n \theta\right)
$$

He re the coefficients $A_{00}, A_{\text {no }}$ and $B_{\text {no }}$ are known due to boundary condition (2.3). All the coefficients $A_{01}, A_{n 1}$ and $B_{n i}(1=1,2, \ldots, N)$ are unknown. Accordingly, the following system of linear equations is obtained:

$$
\begin{aligned}
& \overline{\mathrm{E}}^{0} \overline{\mathrm{A}}_{0}=\overline{\mathrm{G}}^{0} \\
& \overline{\mathrm{E}}^{1} \overline{\mathrm{A}}_{\mathrm{n}}=\overline{\mathrm{G}}^{1} \\
& \overline{\mathrm{E}}^{2} \overline{\mathrm{B}}_{\mathrm{n}}=\overline{\mathrm{G}}^{2}
\end{aligned}
$$

where $\bar{E}=\left[E_{1 j}^{v}\right](1=1(1) N, j=1(1) N)$ are square matrices of order $N$. 
$\vec{A}_{0}=\left[A_{0 i}\right], \bar{A}_{n}=\left[A_{n i}\right], \bar{B}_{n}=\left[B_{n i}\right]$ and, $\bar{G}^{v}=\left[G_{1}^{v}\right]$ where $1=1(1) N$, are vectors. $E_{i j}^{V}, A_{O i}, A_{n i}, B_{n i}$ and $G_{i}^{V}$ are constants and they depend on the parameters mentioned earlier. He re only a special case in which the annular cross-section of the limb has been divided into two layers 1.e. $\mathrm{N}=2$ is considered. These two layers have different biological properties. The outermost layer is supposed to be made of mainly dead tissues. Hence it does not have any metabolic heat generation or blood flow. These quantities have been prescribed in the inner annular part. The core of the 1 imb is ass umed to have unsymmetric temperature. Parabolic variation of temperature along the circular boundary has been taken, so

$$
V_{0}=F(\theta)=\frac{(\theta-\pi)(\theta-2 \pi)}{2 \pi^{2}} w_{0}+\frac{2 \theta(\theta-2 \pi)}{\left(-2 \pi^{2}\right)} w_{1}+\frac{\theta(\theta-\pi)}{2 \pi^{2}} w_{0}
$$

where $w_{0}=\left(u_{b}-u_{\alpha}\right) / u_{b}, w_{1}=\left(u_{b}-u_{\beta}\right) / u_{b}, u_{\alpha}$ and $u_{\beta}$ are temperatures at

$\theta=0$ and $\theta=\pi$ respectively. Using $F(\theta)$ in terms of Fourler series, the constants $A_{00}, A_{n o}$, and $B_{n o}$ are determined and then substituted in the system of equations $(2: 10)$. These equations are solved to find the values of $A_{01}, A_{n 1}$, and $B_{n 1}$ which in turn are substituted in expressions (2.9) to obtain $v_{1}$. Using (2.5) and (2.9), the temperature profiles are obtained for each sub-region.

\section{NUMERICAL RESULTS}

The following values of physical and physiological parameters and constants have been taken:

$$
\begin{aligned}
& \mathrm{K}_{1}=0.06 \mathrm{Ca} 1 / \mathrm{cm}-\mathrm{min} \text {. deg. } \mathrm{C}, \mathrm{K}_{2}=0.03 \mathrm{Ca} 1 / \mathrm{cm}-\mathrm{min} \cdot \mathrm{deg} \cdot \mathrm{C} \text {, } \\
& a_{0}=2.5 \mathrm{~cm}, a_{1}=5 \mathrm{~cm}, a_{2}=7.5 \mathrm{~cm}, L=579 \mathrm{Ca} 1 / \mathrm{gm} \text {, } \\
& \mathrm{h}=0.009 \mathrm{Ca} 1 / \mathrm{cm}^{2} \text { min. deg. C, } \mathrm{u}_{\mathrm{b}}=37^{\circ} \mathrm{C} \text {, } \\
& M_{1}=\left(m_{b} c_{b}\right)_{1}=0.003 \mathrm{ca} 1 / \mathrm{cm}^{3} \text { min. deg. } C, M_{2}=\left(m_{b} c_{b}\right)_{2}=0 \\
& \text { (s) }{ }_{1}=s_{1}=0.0357 \mathrm{Ca} 1 / \mathrm{cm}^{3}-\mathrm{mi} \mathrm{n},(\mathrm{s})_{2}=\mathrm{s}_{2}=0 \text {, } \\
& u_{\alpha}=30^{\circ} \mathrm{C}, u_{\beta}=34^{\circ} \mathrm{C}, u_{a}=15^{\circ}, E=0 \text {, }
\end{aligned}
$$

Graphs have been plotted between $u$ and $\theta$ and the temperature profiles have been shown in fig. 2, 3 and, 4. Fig. 2 is a geometrical representation of the boundary conditions and figures 3 and 4 give temperature variation in direction around the two annular partitions. These two curves are significantly different from the curve in Fig. 2. There is a slow rise in the temperature at $\theta=0$. This rise becomes sharper later on and obviously the temperature takes on its maximum value at $\theta=\pi$. The 11 near variation of temperature with respect to $r$ is easily seen by comparing the figures 3 and 4.

The number of computations involved in this method are less as compared to those in variational finite element method for two dimensional case. 


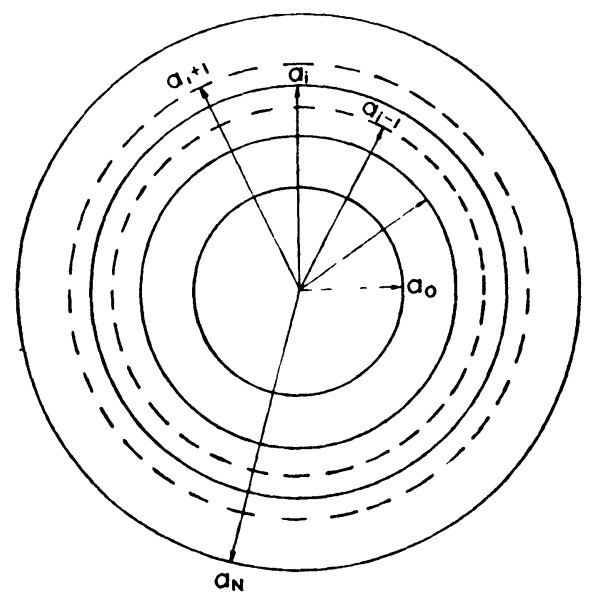

Fig. 1. ANNULAR CROSS-SECTION OF A HUMAN LIMB DIVIDED INTO N LAYERS. SHADED PORTION IS SOLID CIRCULAR SECTION.

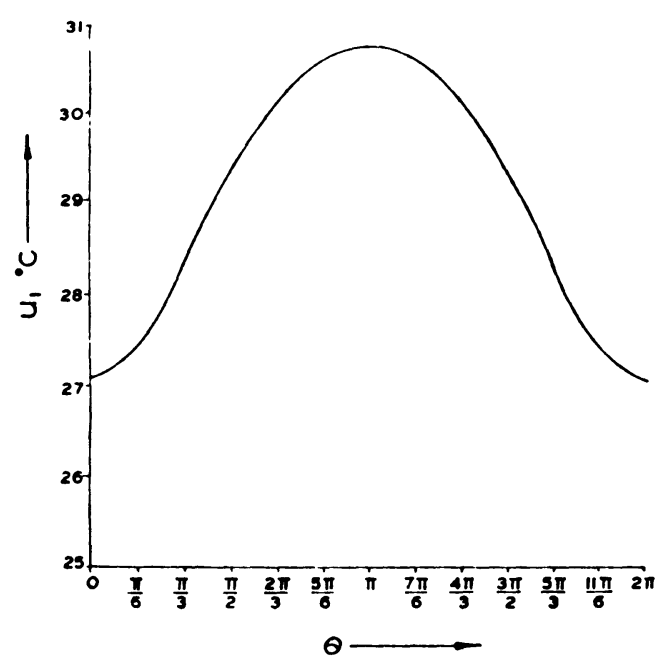

Fig. 3. GRAPH BETWEEN $U_{1}$ AND $\odot$, SHOWING THE TEMPERATURE VARIATIONS AROUND THE INNER ANNULAR PARTITION.

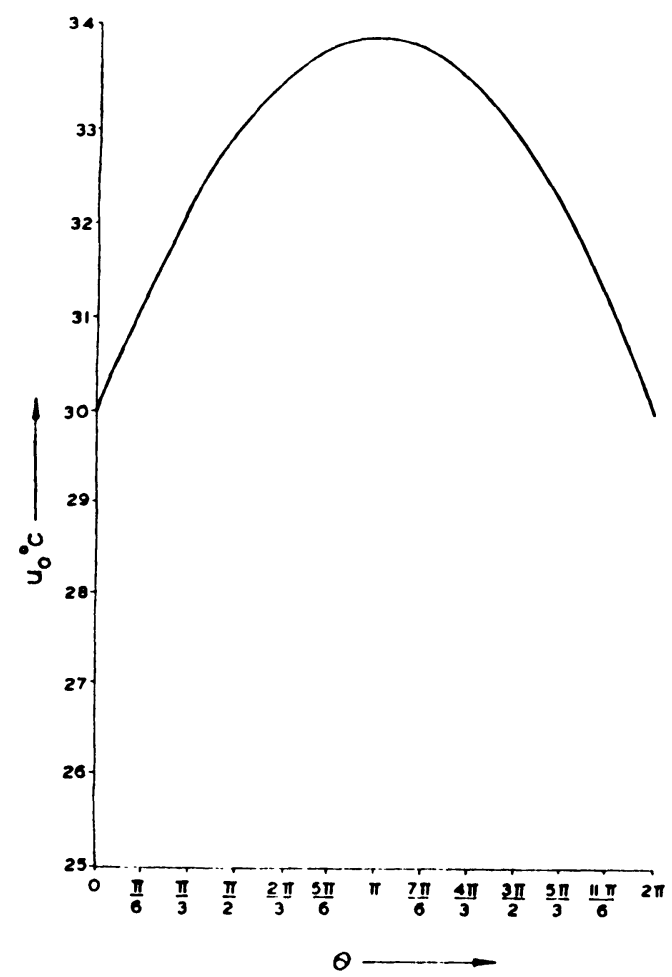

Fig.2. GRAPH SHOWING THE GEOMETRICAL REPRESENTATION OF THE BOUNDARY CONDITIONS.

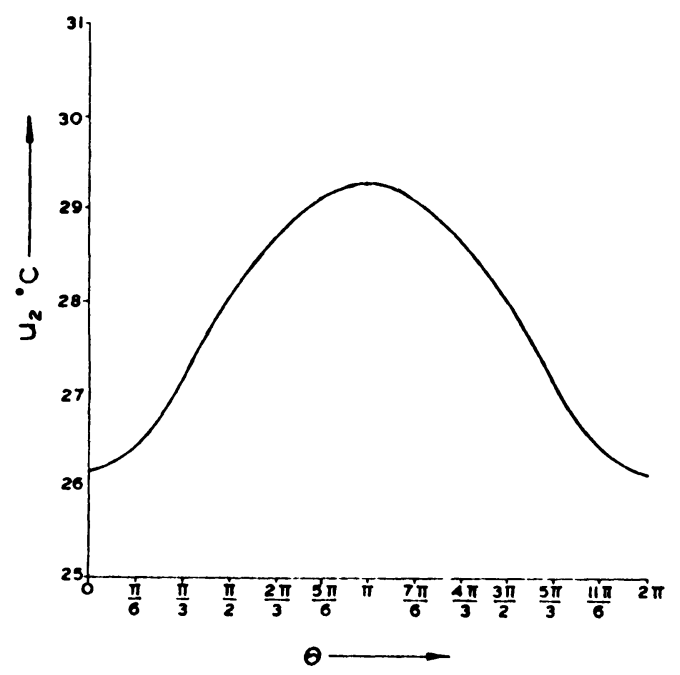

Fig. 4. GRAPH BETWEEN U 2 AND $\theta$, SHOWING THE TEMPERATURE 2 VARIATIONS AROUND THE OUTER ANNULAR PARTITION. 


\section{REFERENCES}

1. PERL, W., Heat and Water Migration in Body Tissues and Determination of Tissue Blood F1 ow by Local Clearance Methods, J. Theo, Biol. 2 (1962), 201-235.

2. CHAO, K.N., EISELY, J.G. and YANG, W.J., Heat and Water Migration in Regional Skins and Subcutaneous Tissues, Bio-Mech symp. ASME, 1975, 69-72.

3. CHAO, K.N. and YANG, W.J., Response of Skin and Tissue Temperature in Sauna and Steam Baths, Bio-Mech. symp., ASME, 69-71.

4. COOPER, T.E. and TREZEK, G.J., Analytical Determination of Cylindrical Source Temperature Fields and their Relation to Thermal Diffusivity of Brain Tissues, Thermal Problems in Bio-Technology, ASME, 1968, NY, 1-15.

5. SAXENA, V.P., Application of Similarity Transformation to Unsteady State heat Migration Problems in Human SST, Proc. 6th Int. Heat. Trans. Conf. Vol. III, $1978,65-68$.

6. SAXENA, V.P., Temperature Distribution in Human Skin and Subderma1 Tissues, J. Theo. Biol., 1983, 102, 277-286.

7. SAXENA, V.P. and ARYA, D., Exact Solution of the Temperature Distribution Problem in Epidermis and Dermis Regions of Human Body. Proc. VNM, Medical and Biological Engineering, Sweden, 1981, 364-366.

8. SAXENA, V.P. and ARYA, D., Variational Finite Element Approach to Heat Distribution Problems in Human Skin and Subdermal Tissues, Proc. Ist Int. Conf. Numerical Methods in Thermal Problems, Pineridge Press, U.K., 1979, 1067-1076.

9. SAXENA, V.P. and BINDRA, J.S., St eady St ate Temperature Distribution in Dermal Regions of Human Body with Variable Blood Flow, Perspiration and Self controlled Metabolic Heat Generation, Ind. J. Pure app. Math, 15(1), $1984,31-42$.

10. SAXENA, V.P. and BINDRA, J.S., Quadratic Shape Functions in Variational Finite Element Approach to Heat Distribution in Cutaneous and Subcutaneous Tissues, Ind. J. Pure App1. Math. 18(9), 1987, 846-855.

11. ARYA, D., Two Dimensional Steady State Temperature Distribution in Skin and Subcutaneous Tissues, Ind. J. Pure Appl. Math.12(1), 1981, 1361-1371.

12. ARYA, D. and SAXENA, V.P., Temperature Variation in Skin and Subcutaneous Layers Under Different Envi ronmental Conditions- A Two Dimensional Study, Ind. J. Pure. Appl. Mathe 17(1), 1986, 84-99.

13. SAXENA, V.P. and BINDRA, J.S., Two Dimensional Steady st ate Temperature Distribution in Non-Uniform Dermal Layers with Variable Physical and Physiological Conditions. (Under Publication). 


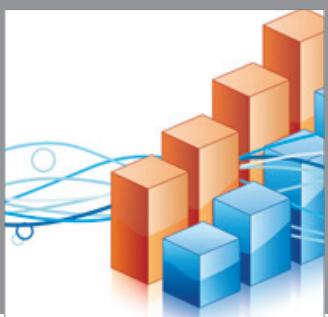

Advances in

Operations Research

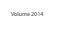

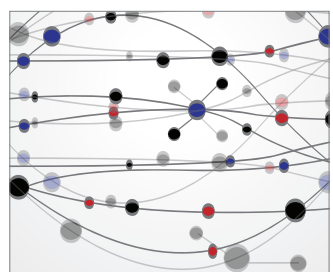

\section{The Scientific} World Journal
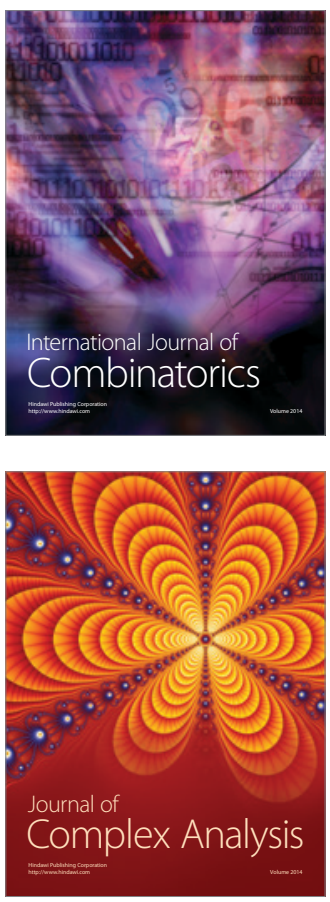

International Journal of

Mathematics and

Mathematical

Sciences
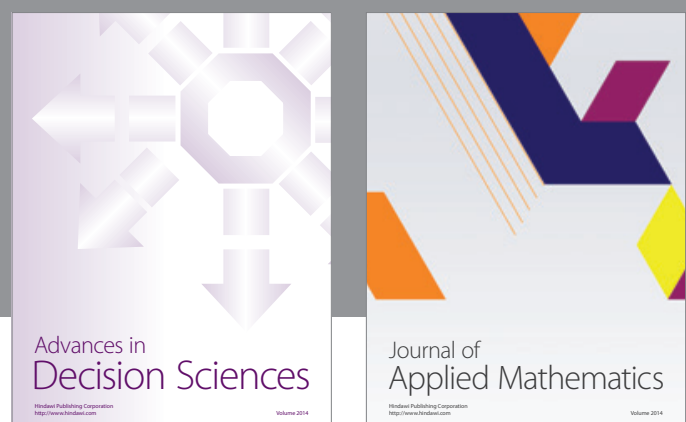

Journal of

Applied Mathematics
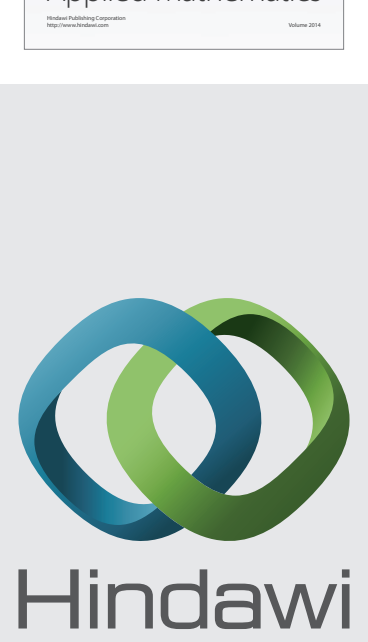

Submit your manuscripts at http://www.hindawi.com
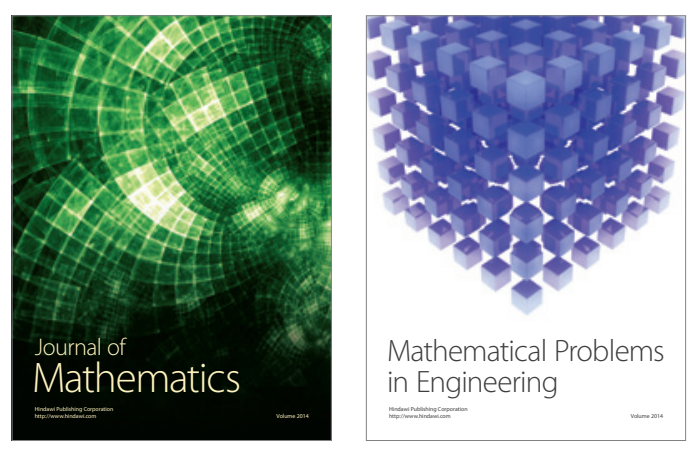

Mathematical Problems in Engineering
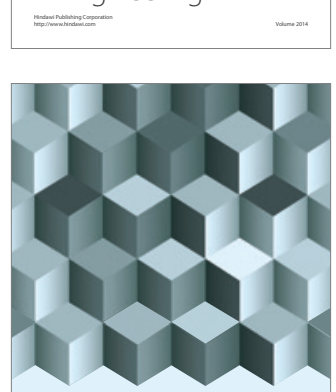

Journal of

Function Spaces
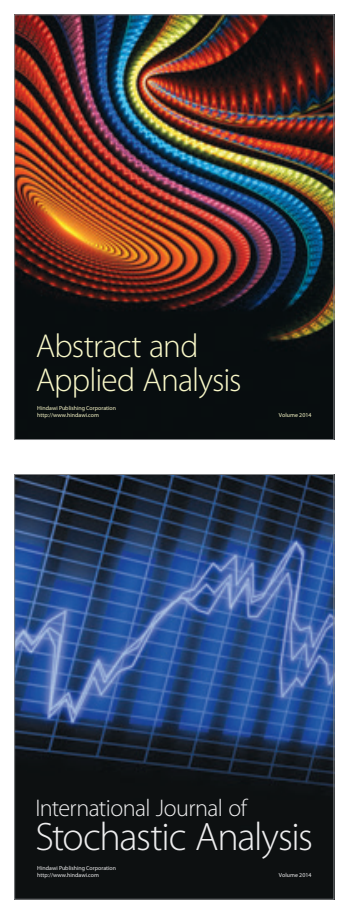

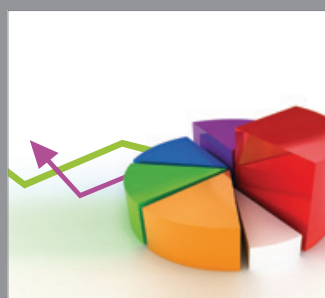

ournal of

Probability and Statistics

Promensencen
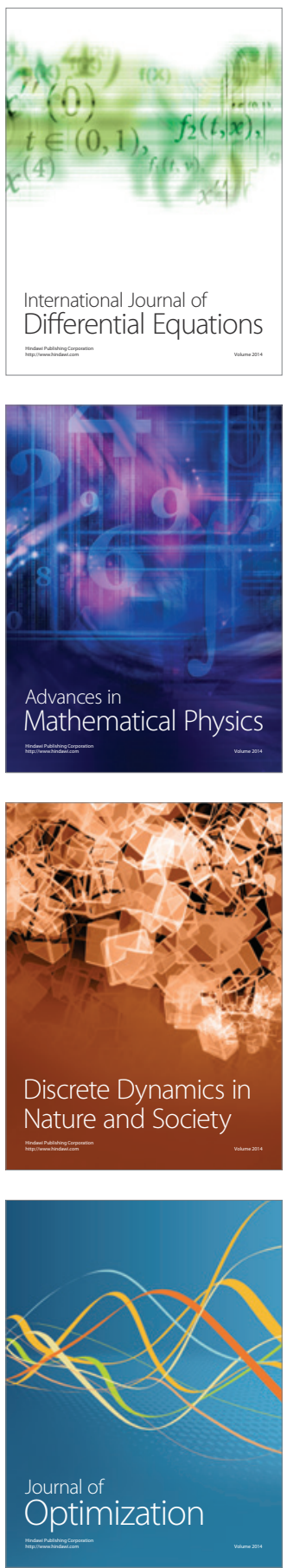